\title{
The investigation of supply chain's reliability measure: a case study
}

Houshang Taghizadeh ${ }^{1 *}$ and Ehsan Hafezi ${ }^{2}$

\begin{abstract}
In this paper, using supply chain operational reference, the reliability evaluation of available relationships in supply chain is investigated. For this purpose, in the first step, the chain under investigation is divided into several stages including first and second suppliers, initial and final customers, and the producing company. Based on the formed relationships between these stages, the supply chain system is then broken down into different subsystem parts. The formed relationships between the stages are based on the transportation of the orders between stages. Paying attention to the system elements' location, which can be in one of the five forms of series namely parallel, series/ parallel, parallel/series, or their combinations, we determine the structure of relationships in the divided subsystems. According to reliability evaluation scales on the three levels of supply chain, the reliability of each chain is then calculated. Finally, using the formulas of calculating the reliability in combined systems, the reliability of each system and ultimately the whole system is investigated.
\end{abstract}

Keywords: Supply chain, Reliability, Supply chain operational reference

\section{Background}

The supply chain includes all the activities related to the processing of materials and the conversion of goods from the stage of raw material to the stage of delivery to the final customer, as well as the informational and financial processes related to them, along with coordinated and integrated management (Shafia et al. 2008). In a broader sense, a supply chain consists of two or more organizations that could be companies which produce parts, constituents, and final products or they could even include the supply-and-distribute service providers or the final customer as well (Supply Chain Council 2008). The most important factor in the successful management of the supply chain is a reliable relationship among the partners in the chain in such a way that they can have mutual trust in each others' capabilities and activities. Therefore, in the development of any integrated supply chain, increasing the confidence and trust among the partners and devising the reliability for them are the crucial factors to achieve sustainable success (Ghazanfari and Fatholla 2006). In the current industries, choosing business partners and

\footnotetext{
* Correspondence: taghizadeh@iaut.ac.ir

'Department of Management, Tabriz Branch, Islamic Azad University, Tabriz, Iran

Full list of author information is available at the end of the article
}

establishing a successful and sustainable communication with them regarding the previous standards and criteria is not feasible. Hence, determining the quantitative criteria and parameters through which the most suitable partner could be chosen seems to be useful. The reliability factor is also one of the most effective criteria which mean the probability of the intact and flawless performance of the system for a definite and pre-scheduled period of time (Haj Shirmohammadi 2002). On these grounds, the present paper aims to study the reliability rate in the supply chain model and to determine whether the relationships within the supply chain have a high reliability rate or not. In order to study this, the 'supply chain operational reference' (SCOR), which is a valuable tool to analyze supply chains, has been used. The SCOR model supports the operational evaluation metrics at three levels. The metrics of level one provide an approach to supply chain in order to assess management, and the metrics of levels two and three include more specific and detailed criteria regarding the categories and elements of the processes. The metrics of level one are systematically divided into five operational criteria, three of which, reliability, flexibility, and responsiveness, are customer-facing attributes, and the other two, costs and assets, are internal-facing ones. Each of these metrics 
is further divided into minor metrics at the lower levels (Supply Chain Council 2006). The rate of reliability, which is the operational criterion discussed in this article, is also assessed and measured at level one of the supply chain based on SCOR model through the metrics of perfect order fulfillment; at level two through the metrics of perfect order fulfillment, delivery performance to customer commit date, accurate documentation, and perfect condition of order (Stephan and Badr 2007). Level three of the supply chain under study also has minor and more detailed metrics for the assessment of the above-mentioned metrics. It is possible to calculate the reliability rate of each loop of the broad chain under study during different pre-scheduled time periods. In order to measure the reliability rate of the whole supply chain under study at a certain period of time, first, it is necessary to identify the type of the supply chain formed in one of the five positions-series, parallel, series/parallel, parallel/series, or composite, and then, based on the reliability formula of the related system, it is possible to calculate the reliability of the whole system at that period (Haj Shirmohammadi 2002).

In comparison with previous studies, by calculating reliability measurement metrics in different levels of the supply chain and identifying the impact value of each of these metrics on variances of reliability criterion in different periods, this research has been able to offer a new method for prioritizing decreasing reliability factors in a supply chain in order to reduce their effects. In addition, this research is a case study in Iran which is suitable for computing reliability of supply chain for Iranian organizations.

\section{Case description}

The case study provided in this paper is that of Tabriz Iran Khodro Factory (TIKF) and its suppliers and sale delegates. TIKF is a car-producing factory.

\section{Review of literature}

The scope and boundaries of cooperation among the constituents of the supply chain include various activities of which predicting the amount of the material needed, ordering the raw material, processing and carrying out orders, supervising the transport services, distributing the final product controlling the bill, and reviewing payment mode can be cited as examples (Bozarth and Handfield 2007). Figure 1 shows the main activities of the supply chain.

The existence of fault in meeting the needs and expectations in every part of a chain causes the progressive increase in problems, and defect in one part of the system creates problems in other parts. This chain-like state prevails and creates even more problems. One of the key indices in increasing the competitive and qualitative power of the products and production services of organizations and institutes is creating and establishing reliable relationship with the chain of providers and suppliers of raw material and primary parts, and the careful assessment of the reliability rate of these relationships. The success or failure of each supply chain in the market is eventually determined by the final customer or the consumer. Thus, in order to establish a successful new relationship in the supply chain, assessing the reliability of the relationship is among the crucial factors in this field (Xujie 2009).

The SCOR model, which is a means of analyzing and configuring the supply chain, was devised by the Supply Chain Council. It was established by the Institute of Advanced Manufacturing Research, PRTM Counseling Company, and more than 65 major companies. It currently has over 850 members around the world.

The SCOR metrics are applied in relation with operation attributes. Operation attributes are the supply chain attributes through which it is possible to analyze and assess the company's supply chain strategy at each level separately and to compare it with other strategies. The metrics of level one are systematically divided into five classes, i.e., reliability, flexibility, and responsiveness, which are customerfacing attributes, and costs and assets, which are internalfacing attributes (Table 1; Supply Chain Council 2006).

Each of these metrics is further divided into minor metrics at the lower levels of the model, which are codified according to the format below (Table 2).

This is an easier way to eliminate errors during activities such as benchmarking of the supply chain and the like. The metrics' number format is XX.y.z, in which $y$ is the metric level, $z$ is the specific number, and XX is the operation attribute.

The possible values for $\mathrm{XX}$ include reliability (RL), responsiveness (RS), flexibility (AG), costs (CO), and assets (AS) (Supply Chain Council 2006). The operation attribute is the reliability of the attribute under discussion in this article. The codification and calculation manners of each metric at the three levels of reliability attribute have been shown in Tables 2 and 3, respectively.

As mentioned before, a system usually consists of a number of constituent elements, or a number of smaller systems, or subsystems; the juxtaposition of which as well as their dependence on each other will influence the reliability of the system (Han et al. 2007). The constituents of a system are linked to each other in one of the five positions: series, parallel, parallel/series, series/parallel, and composite. Table 4 shows the structure and calculation manner of the reliability of each position.

At present, the subject of supply chain is of great interest among the world researches and articles in this regard. These researches include introducing various types of mathematical models, different managerial techniques, methods of control, and other topics concerning industrial 


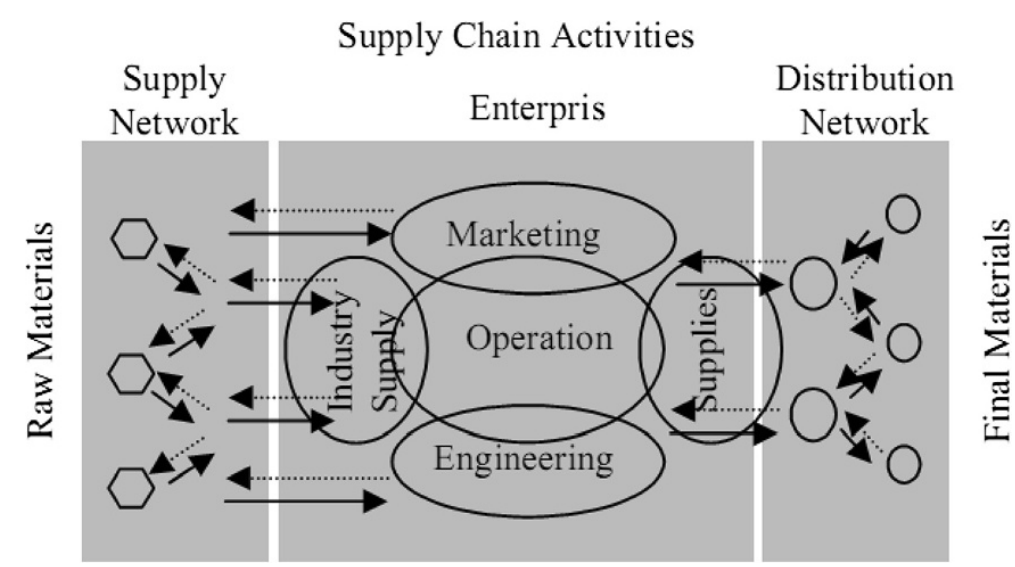

Figure 1 The main activities of the supply chain. Adapted from Bozarth and Handfield (2007).

engineering and management, especially supply chain management.

Some of the researches are as follows: Jabbour et al. (2011) have been studying to perform an empirical investigation about the constructs and indicators of the supply chain management practices framework. Banomyong and Supatn (2011) presented a supply chain performance assessment tool that measures the performance of key supply chain activities of a firm under different performance dimensions. Christopher et al. (2011) studied to understand how managers assess global sourcing risks across the entire supply chain and what actions they take to mitigate those risks. Seifbarghy et al. (2010) analyzed the supply chain using the SCOR model in a steel producing company. Tian (2009) researched on equilibrium of coordination reliability of supply chain and deepening in division of labor in the perspective of dilemma. Lin (2009) studied system reliability evaluation for a multistate supply chain network with failure nodes using minimal paths. Xujie (2009) has done modeling and analyzing supply chain reliability by different effects of failure nodes. Jahandideh (2008) studied and assessed the process of managing car parts suppliers' chain in SAPCO Company. Klimov and Merkuryev (2008) presented a simulation model for supply chain reliability evaluation. Qing-kui (2008) studied the reliability analysis and evaluation on member enterprise of manufacturing supply chain based on BP neural network. Lirong Cui (2008) studied on reliability of supply chain based on higher order Markov chain. Hwang et al. (2008) evaluated the sourcing process in the SCOR model in the manufacturing industries of Taiwan. Stephan and Badr (2007) presented quantitative and qualitative approaches to manage risks in the supply chain operations reference. Han et al. (2007) reviewed and analyzed supply chain operations reference. Similarly, various studies have been done on supply chain and SCOR model in Iran,

Table 1 Level one metrics of an SCOR model

\begin{tabular}{|c|c|c|c|c|c|}
\hline \multirow[t]{3}{*}{ Level one metrics } & \multicolumn{5}{|c|}{ Performance attributes } \\
\hline & \multicolumn{3}{|c|}{ Customer facing } & \multicolumn{2}{|c|}{ Internal facing } \\
\hline & Reliability & Responsiveness & Flexibility & Costs & Assets \\
\hline Perfect order fulfillment & * & & & & \\
\hline Order fulfillment cycle time & & * & & & \\
\hline Upside supply chain flexibility & & & * & & \\
\hline Upside supply chain adaptability & & & * & & \\
\hline Downside supply chain adaptability & & & * & * & \\
\hline Supply chain management cost & & & & * & \\
\hline Cost of goods sold & & & & * & \\
\hline Cash-to-cash cycle time & & & & & * \\
\hline Return on supply chain fixed assets & & & & & $*$ \\
\hline Return on working capital & & & & & * \\
\hline
\end{tabular}

Each asterisk shows the relationship between metric levels and performance attributes. Adapted from Supply Chain Council (2006). 
Table 2 Codification of metrics at three levels of operation attribute of reliability in the SCOR model

\begin{tabular}{lll}
\hline Level & Code & Metric \\
\hline One & RL.1.1 & Perfect order fulfillment \\
Two & RL.2.1 & Percentage of orders delivered in full \\
& RL.2.2 & Delivery performance to customer commit date \\
RL.2.3 & Accurate documentation \\
RL.2.4 & Perfect condition \\
Three & RL.3.1 & Delivery quantity accuracy \\
RL.3.2 & Delivery item accuracy \\
RL.3.3 & Customer commit date achievement time customer \\
& receiving \\
RL.3.4 & Delivery location accuracy \\
RL.3.5 & Shipping documentation accuracy \\
RL.3.6 & Compliance documentation accuracy \\
RL.3.7 & Payment documentation accuracy \\
RL.3.8 & Orders delivered damage free conformance \\
RL.3.9 & Orders delivered defect free conformance \\
RL.3.10 & Percentage of faultless installations \\
RL.3.11 & Warranty and returns
\end{tabular}

Adapted from Stephan and Badr (2007).

some of which can be cited here. Liu et al. (2007) studied the performance of the supply chain in relation to assessing its reliability. Huan et al. (2004) developed in a case study in China a collaborative supply chain reference model. Hezarkhani (2006) focused on the promotion of supply chain performance, using SCOR model. Ren et al. (2006) suggested a framework based on SCOR model to manage supply chain performance. Satitsatian and Kapur (2005) devised an algorithm for reliability bound computation to assess supply chain networks. Shepherd and Gunter (2006) developed methods of determining supply chain reliability for a probable computation system based on the theory of reliability. Manavizadeh (2005) presented a system of measuring the performance in the supply chain in order to establish genuine production. Lockamy and McCormack (2004) examined the link between planning methods in the SCOR model for supply chain performance. Zarei Yaraki (2004) studied sharing information in the supply chain of the country's automobile industry. Riazy (1997) devised a decision-making method for evaluation, selection, and development of suppliers in supply chain management. Azimi (2001) focused on measuring supply chain performance. Teimouri (1999) expanded the model for suppliers' selection and distribution from the standpoint of supply chain management.

\section{Research scope and data collection method}

The supply chain structure shown in Figure 2 is a sixstage supply chain whose function is providing raw
Table 3 Manner of calculating the metrics at three levels of the SCOR model

\begin{tabular}{|c|c|}
\hline Code & Calculation \\
\hline RL.1.1 & [Total perfect orders $] /[$ Total number of orders $]$ \\
\hline RL.2.1 & $\begin{array}{l}\text { [Total number of orders delivered in full]/[Total number of } \\
\text { orders delivered] }\end{array}$ \\
\hline RL.2.2 & $\begin{array}{l}\text { Total number of orders delivered on the original commitment } \\
\text { date]/[Total number of orders delivered] }\end{array}$ \\
\hline RL.2.3 & $\begin{array}{l}\text { [Total number of orders delivered with accurate } \\
\text { documentation]/[Total number of orders delivered] }\end{array}$ \\
\hline RL.2.4 & $\begin{array}{l}\text { [Number of orders delivered at perfect condition]/[Total } \\
\text { number of orders delivered] }\end{array}$ \\
\hline RL.3.1 & $\begin{array}{l}\text { [Total perfect orders without item defect]/[Total number of } \\
\text { orders] }\end{array}$ \\
\hline RL.3.2 & $\begin{array}{l}\text { [Number of orders delivered without item defect quantity]/ } \\
\text { [Total number of orders] }\end{array}$ \\
\hline RL.3.3 & $\begin{array}{l}\text { [Number of orders delivered without time defect]/[Total } \\
\text { number of orders] }\end{array}$ \\
\hline RL.3.4 & $\begin{array}{l}\text { [Number of orders delivered without location defect]/[Total } \\
\text { number of orders] }\end{array}$ \\
\hline RL.3.5 & $\begin{array}{l}\text { [Number of orders delivered without shipping documentation } \\
\text { defect ]/[Total number of orders] }\end{array}$ \\
\hline RL.3.6 & $\begin{array}{l}\text { [Number of orders delivered without compliance } \\
\text { documentation defect]/[Total number of orders] }\end{array}$ \\
\hline RL.3.7 & $\begin{array}{l}\text { [Number of orders delivered without payment documentation } \\
\text { defect]/[Total number of orders] }\end{array}$ \\
\hline RL.3.8 & $\begin{array}{l}\text { [Number of orders delivered without damage in order]/[Total } \\
\text { number of orders] }\end{array}$ \\
\hline RL.3.9 & $\begin{array}{l}\text { [Number of orders delivered without defect in order]/[Total } \\
\text { number of orders] }\end{array}$ \\
\hline RL.3.10 & $\begin{array}{l}\text { [Total perfect orders delivered without installation problems in } \\
\text { order]/[Total number of orders] }\end{array}$ \\
\hline RL.3.11 & $\begin{array}{l}\text { [Total perfect orders delivered without warranty defect in } \\
\text { order]/[Total number of orders] }\end{array}$ \\
\hline
\end{tabular}

Adapted from Stephan and Badr (2007).

materials from the supplier, producing the product, and delivering it to the final customer. The first through third stages include the suppliers; the fourth stage includes the producing company, and the fifth and sixth stages include the primary and final customers. The research population and the research scope involve the second through the fifth stages. Since the main focus of the research is to study the reliability rate of the supply chain, the research method is descriptive, and in order to obtain the desired result, a combination of library studies including review of the available documents and evidence has been done.

\section{Research model}

If the chain under study is divided, based on the inter-stage relations, into three parts $\mathrm{A}, \mathrm{B}$, and $\mathrm{C}$ and each part is considered as a subsystem, then each of the created relations in each subsystems $A, B$, and C 
Table 4 Manner of calculating the reliability of different positions in a systems

Sesition

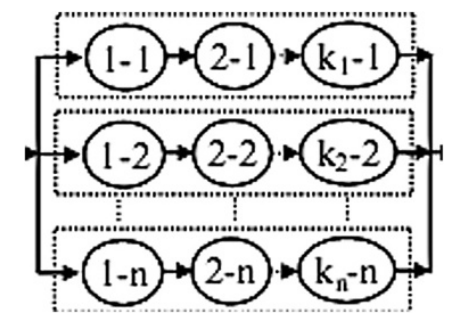

$$
\mathrm{RL}_{s}=1-\prod_{j=1}^{n}\left[\left(1-\prod_{j=1}^{k} P_{i, j}\right)\right]
$$

\section{Stage 1 Stage 2 Stage 3 Stage 4 Stage 5 Stage 6}

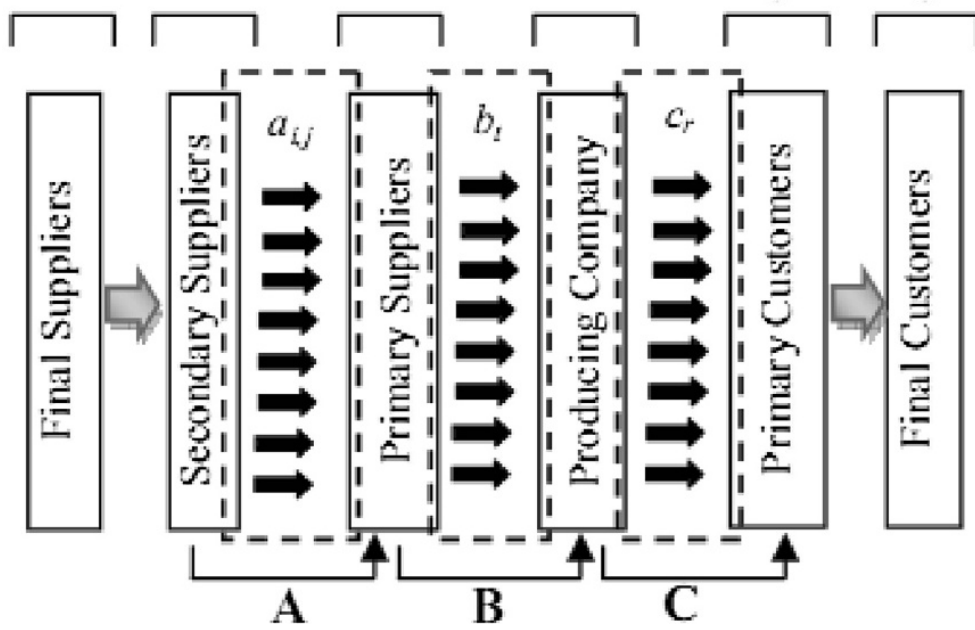

Figure 2 Supply chain structure. 
will be shown by the symbols $a_{i, j}, b_{t}$, and $c_{n}$ respectively. Symbol $a_{i, j}$ serves to transfer order from the secondary supplier to the primary supplier; $b_{t}$ functions to transfer the order from the primary supplier to the producing company, and $c_{r}$ serves to transfer the order from the producing company to the primary customers.

In subsystem $\mathrm{A}$, in case of failure in providing one kind of order from a secondary supplier for any reason, it is possible to obtain the order from another secondary supplier; thus, because of the inability to provide one kind of order, subsystem A will be inefficient. Therefore, in subsystem A, different types of orders are reciprocally dependent, while the suppliers of the same kind of order are independent of each other. Thus, $a_{i, j}$ forms a series/ parallel structure. Likewise, in subsystem $B$, in case of inability to provide one kind of order, subsystem B will be inefficient. Therefore, in subsystem $B$, different kinds of orders are dependent on each other. As a result, $b_{t}$ forms a series structure. However, in subsystem $C$, in case of inability to transfer the order from the producing company to a certain customer, subsystem $\mathrm{C}$ will not be inefficient; rather, it will be inefficient only if the transfer of order is not done to any of the primary customers. Thus, in subsystem $C$, the primary customers are independent of each other. As a result, $c_{r}$ forms a parallel structure (Figure 3).

In this paper, in order to analyze the supply chain reliability based on the SCOR model, the reliability evaluation metrics are calculated at 12 different periods of time, with each period considered to last one month. The threelevel metrics based on RL.y.z format have been shown in Table 2. Therefore, in order to obtain the values of the three-level metrics and to analyze the reliability of the whole chain, the RL.y.z values should be calculated for each subsystem (A, B, and C). Thus, the reliability of subsystems $\mathrm{A}, \mathrm{B}$, and $\mathrm{C}$ will be calculated through the relations (Equations 1, 2, and 3), respectively:

$$
\begin{aligned}
& \mathrm{RL} \cdot y \cdot z_{\mathrm{A}}=\prod_{i=1}^{k}\left[1-\prod_{j=1}^{n}\left(1-\mathrm{RL} \cdot y \cdot z_{a_{i j}}\right)\right], \\
& \mathrm{RL} \cdot y \cdot z_{\mathrm{B}}=\prod_{t=1}^{l} \mathrm{RL} \cdot y \cdot z_{b_{t}}, \\
& \mathrm{RL} \cdot y \cdot z_{\mathrm{C}}=1-\prod_{r=1}^{m}\left(1-\mathrm{RL} \cdot y \cdot z_{c_{r}}\right) .
\end{aligned}
$$

In those relations (Equations 1, 2, and 3), the following have been defined:

- RL.y.z is the reliability of the metric number $z$ from level $y$.

- $a_{i, j}$ is the subsystem transferring the order type $i$ from the secondary supplier $j$.

- $b_{t}$ is the subsystem transferring the order type $t$ from the primary supplier.

- $c_{r}$ is the subsystem transferring the order to the primary customer $r$.

- $y$ is the number of the level $(y=1,2,3, \ldots, p)$.

- $z$ is the number of the metric $(z=1,2,3, \ldots, q)$.

- $i$ is the number of the order type transferred from the secondary supplier to the primary supplier $(i=1,2$, $3, \ldots, k)$.

- $j$ is the number of the secondary supplier $(j=1,2,3$, $\ldots, n)$.

- $t$ is the number of the order type transferred from the

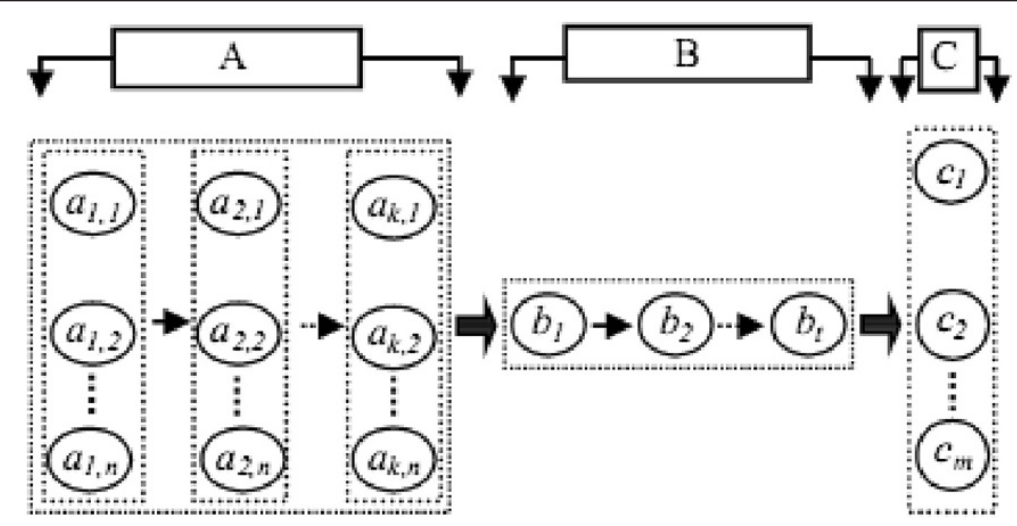

Figure 3 Inter-stage relations structure in the supply chain. 
Table 5 RL.1.1 metric values in subsystems A, B, and C

\begin{tabular}{lccc}
\hline Month & A & B & C \\
\hline Farvardin & 0.779 & 0.856 & 0.849 \\
Ordibehesht & 0.782 & 0.863 & 0.848 \\
Khordad & 0.794 & 0.83 & 0.844 \\
Tir & 0.824 & 0.901 & 0.844 \\
Mordad & 0.837 & 0.895 & 0.843 \\
Shahrivar & 0.828 & 0.893 & 0.84 \\
Mehr & 0.84 & 0.907 & 0.843 \\
Aban & 0.833 & 0.898 & 0.841 \\
Azar & 0.839 & 0.905 & 0.838 \\
Day & 0.839 & 0.901 & 0.843 \\
Bahman & 0.848 & 0.908 & 0.843 \\
Esfand & 0.836 & 0.903 & 0.848 \\
\hline
\end{tabular}

primary supplier to the producing company $(t=1,2$, $3, \ldots, l)$

- $r$

is the number of the primary customer $(r=1,2,3$, $\ldots, m)$

Now, with regard to the fact that subsystems A, B, and C are the independent and serial subsystems of the supply chain under study in this paper, in order to calculate each of the three-level metrics of the whole system, which is shown by the symbol RL.y. $z_{T}$ values, the formula for calculating the reliability of series systems is used:

$$
\text { RL.y. } z_{\mathrm{T}}=\text { RL. } y . z_{\mathrm{A}} \times \text { RL. } y . z_{\mathrm{B}} \times \text { RL.y. } z_{\mathrm{C}}
$$

\section{Discussion and evaluation}

In order to obtain the values of the three-level reliability metrics in different months, at first, the values of RL.y.z were separately studied in each subsystem (A, B, and C).

The RL.1.1 metric values in subsystems A, B, and C for 12 months are shown as an example in Table 5.

Next, by putting the metric values of each subsystem in the relation (Equation 4), the required value of that metric in the whole supply chain was obtained. The values of these metrics are shown in Table 6. In the last column of Table 6, the annual average of the reliability metric values of the whole supply chain has been given.

As is seen in the diagram of level one in Figure 4, in Shahrivar, Aban, and Esfand, the reliability rate regarding perfect order fulfillment shows a relatively low decrease as compared with the related value in the previous month. The reason can be understood by having a glance at the diagrams of levels two and three.

It is seen that in Shahrivar, the reliability is concerning metric (RL.2.4) at level two; at level three, the reliability is concerning metrics (RL.3.6), (RL.3.8), (RL.3.9), and (RL.3.11) which show a considerably sharp decrease, which causes the decrease in the whole supply chain reliability in Shahrivar. In addition, the decline in the rate of metrics (RL.2.3) and (RL.2.4) at level two and the metrics (RL.3.5), (RL.3.7), (RL.3.9), and (RL.3.11) at level three have caused the decrease in the total reliability metrics in Aban. Furthermore, in Esfand the decline in metrics (RL.2.1), (RL.2.2), and (RL.2.3) at level two and the metrics (RL.3.1), (RL.3.2), (RL.3.3), (RL.3.4), (RL.3.5),

Table 6 Reliability evaluation metric values in the whole supply chain under study

\begin{tabular}{|c|c|c|c|c|c|c|c|c|c|c|c|c|c|}
\hline Code & Farvardin & Ordibehesht & Khordad & Tir & Mordad & Shahrivar & Mehr & Aban & Azar & Day & Bahman & Esfand & Average \\
\hline RL.1.1 $1_{\mathrm{T}}$ & 0.556 & 0.572 & 0.582 & 0.626 & 0.631 & 0.621 & 0.642 & 0.629 & 0.636 & 0.637 & 0.649 & 0.64 & 0.619 \\
\hline RL.2.1 $1_{T}$ & 0.916 & 0.922 & 0.919 & 0.936 & 0.934 & 0.935 & 0.922 & 0.934 & 0.927 & 0.926 & 0.936 & 0.929 & 0.928 \\
\hline RL.2.2 $\mathrm{T}$ & 0.885 & 0.905 & 0.884 & 0.898 & 0.907 & 0.92 & 0.919 & 0.923 & 0.918 & 0.926 & 0.936 & 0.929 & 0.928 \\
\hline RL.2.3 T & 0.831 & 0.832 & 0.845 & 0.873 & 0.864 & 0.869 & 0.884 & 0.864 & 0.887 & 0.881 & 0.89 & 0.885 & 0.867 \\
\hline RL.2.4T & 0.847 & 0.832 & 0.856 & 0.86 & 0.87 & 0.838 & 0.865 & 0.852 & 0.85 & 0.851 & 0.846 & 0.85 & 0.851 \\
\hline RL.3.1 $1_{\mathrm{T}}$ & 0.964 & 0.975 & 0.97 & 0.977 & 0.973 & 0.975 & 0.955 & 0.97 & 0.97 & 0.969 & 0.971 & 0.969 & 0.97 \\
\hline Rl.3.2T & 0.951 & 0.945 & 0.947 & 0.958 & 0.957 & 0.959 & 0.957 & 0.964 & 0.955 & 0.956 & 0.965 & 0.959 & 0.956 \\
\hline RL.3.3T & 0.943 & 0.948 & 0.937 & 0.95 & 0.948 & 0.956 & 0.959 & 0.959 & 0.961 & 0.955 & 0.959 & 0.957 & 0.953 \\
\hline RL.3.4T & 0.939 & 0.956 & 0.943 & 0.946 & 0.959 & 0.963 & 0.954 & 0.962 & 0.955 & 0.97 & 0.968 & 0.965 & 0957 \\
\hline RL.3.5T & 0.939 & 0.942 & 0.948 & 0.953 & 0.951 & 0.952 & 0.959 & 0.951 & 0.971 & 0.963 & 0.963 & 0.953 & 0.954 \\
\hline RL.3.6T & 0.94 & 0.941 & 0.943 & 9.56 & 0.956 & 0.954 & 0.955 & 0.961 & 0.956 & 0.954 & 0.965 & 0.967 & 0.954 \\
\hline RL.3.7T & 0.941 & 0.94 & 0.945 & 0.96 & 0.951 & 0.959 & 0.964 & 0.946 & 0.956 & 0.96 & 0.957 & 0.96 & 0.953 \\
\hline RL.3.8T & 0.952 & 0.942 & 0.956 & 0.957 & 0.959 & 0.949 & 0.958 & 0.959 & 0.957 & 0.957 & 0.964 & 0.953 & 0.955 \\
\hline RL.3.9T & 0.958 & 0.953 & 0.956 & 0.958 & 0.967 & 0.963 & 0.967 & 0.952 & 0.955 & 0.961 & 0.955 & 0.959 & 0.959 \\
\hline RL.3.10T & 0.949 & 0.947 & 0.957 & 0.955 & 0.965 & 0.966 & 0.966 & 0.968 & 0.959 & 0.953 & 0.949 & 0.953 & 0.957 \\
\hline $\mathrm{RL} .3 .11_{\mathrm{T}}$ & 0.979 & 0.978 & 0.979 & 0.975 & 0.978 & 0.962 & 0.97 & 0.965 & 0.971 & 0.972 & 0.969 & 0.976 & 0.973 \\
\hline
\end{tabular}




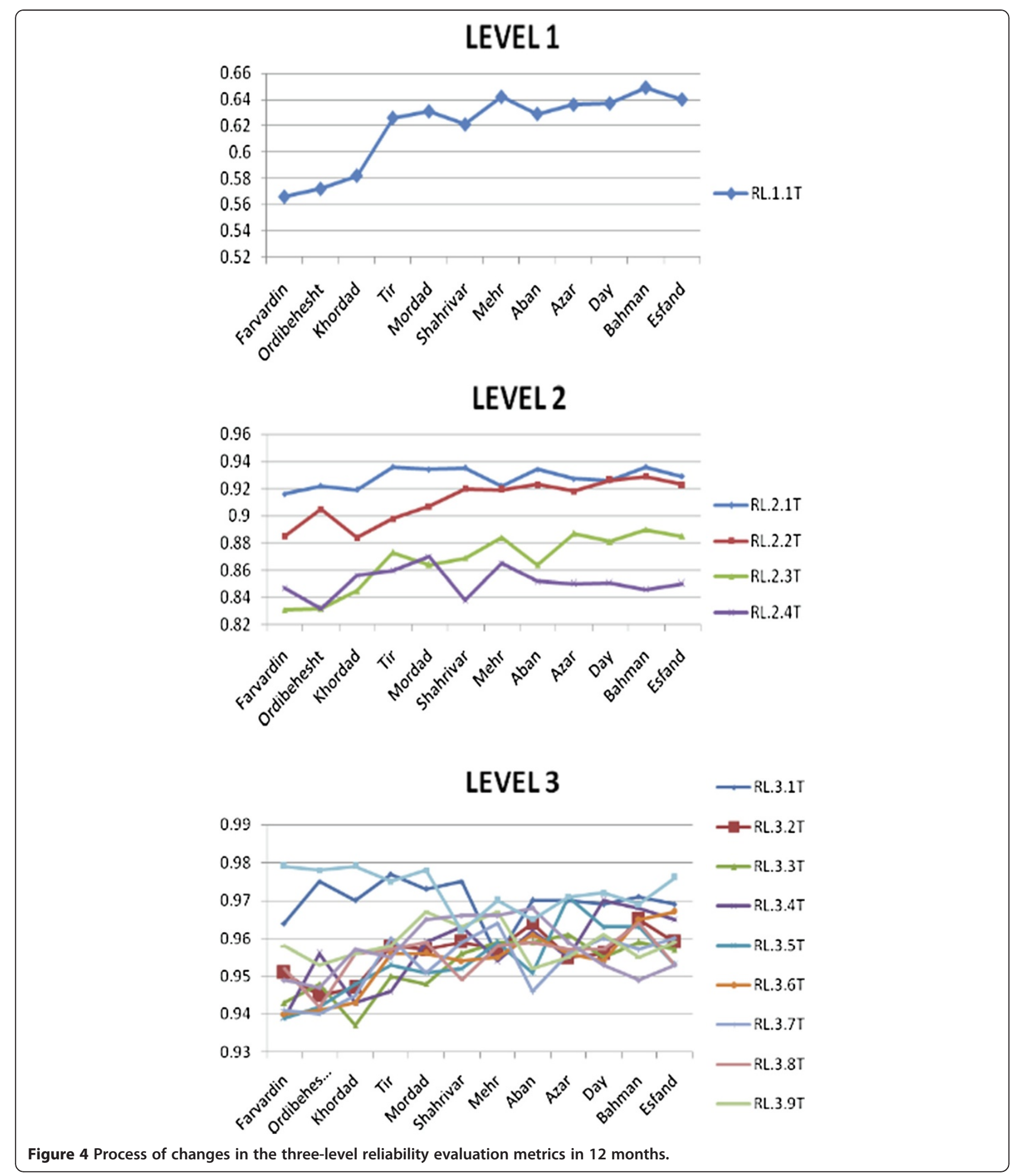

and (RL.3.8) at level three has caused the decrease in the reliability metrics in the whole supply chain.

\section{Conclusions}

The reliability attribute is one of the most important means of measuring and assessing the performance in supply chains. The main purpose of this article is to investigate the reliability measure of the supply chain under study. The data applied in the research are the outcome of library studies including the review of evidence and documents. At first, the supply chain under study was divided into a number of stages, and 
the relations developed among these stages were studied based on the transfer of the order among the stages. Further, according to the relation developed among the different stages, the supply chain system under study was divided into the three subsystems: A, B, and C. Based on the configuration of the elements, the type of subsystems A, B, and C was then determined. Finally, based on the formula of calculating the reliability of compound systems, the reliability of each subsystem A, $\mathrm{B}$, and $\mathrm{C}$ was calculated, according to which the reliability of the whole supply chain was assessed. The main conclusions of the research are as follows:

- The existence of fault in the unloading documentation, the existence of damage and defect in some orders, and the return of reliability warranty time caused the decrease in the reliability of the whole supply chain in Shahrivar by 0.01 .

- The existence of fault in the loading or payment documentation, the existence of defect in the orders, and the return of some of the orders during warranty time caused the decrease in the reliability of the whole supply chain in Aban by 0.013 .

- The existence of fault in material and quantity, inability to deliver to customer commit date, inability to deliver the orders at the accurate location, the existence of fault in the loading documentation, and the existence of defect in some of the orders caused the decrease in the reliability of the whole chain in Esfand by 0.021 .

\section{Competing interests}

The authors declare that they have no competing interests.

\section{Authors' contributions}

Both $\mathrm{HT}$ and $\mathrm{EH}$ have contributed equally in the following sections: Background, Research scope and data collection method, and Research model. HT contributed most of the information in the 'Review of literature' and 'Conclusions' sections, with validating contributions from EH. Both authors read and approved the final manuscript.

\section{Author details}

'Department of Management, Tabriz Branch, Islamic Azad University, Tabriz, Iran. ${ }^{2}$ Industrial Engineering - System Management and Productivity at the Non-Governmental and Private Higher Education Institution of ALGHADIR, Tabriz, Iran.

Received: 2 October 2010 Accepted: 3 March 2012 Published: 2 October 2012

\section{References}

Azimi E (2001) Measuring the supply chain operation. M.Sc. Thesis. Faculty of Technology and Engineering, Teacher Training University, Tehran

Banomyong R, Supatn N (2011) Developing a supply chain performance tool for SMEs in Thailand. Supply Chain Management: An International Journal 16:20-31

Bozarth C, Handfield RB (2007) Introduction to operations and supply chain management, 2nd edn. Prentice Hall, New Jersey

Christopher M, Mena C, Khan O, Yurt O (2011) Approaches to managing global sourcing risk. Supply Chain Management: An International Journal 16:67-81
Ghazanfari M, Fatholla M (2006) A comprehensive look at supply chain management, 1st edn. Iran Science and Technology University Publications, Tehran

Han S, Chu CH, Yang S (2007) Developing a collaborative supply chain reference model: a case study in China. International Conference on Service Operations and Logistics and Informatics, Philadelphia, 27-29 August 2007

Haj Shirmohammadi A (2002) Programming maintenance and repair (Technical management in industry), 8th edn. Ghazal Publishers, Esfahan

Hezarkhani B (2006) Promoting the supply chain operation using SCOR model with Selecting and Expanding Supplier's in the Supply Chain Management. Doctoral Dissertations. Faculty of Technology, Tehran University, Tehran

Huan SH, Sheoran SK, Wang G (2004) A review and analysis of supply chain operations reference (SCOR) model. Supply Chain Management: An International Journal 9:23-29

Hwang YD, Lin YC, Lyu J Jr (2008) The performance evaluation of SCOR sourcing process - the case study of Taiwan's TFT-LCD industry. International Journal of Production Economics 115:411-423

Jabbour A, Filho A, Viana A, Jabbour C (2011) Measuring supply chain management practices. Measuring Business Excellence 15:18-31

Jahandideh D (2008) Evaluating the process of managing car parts supplier's chain in SAPCO. M.Sc. Thesis. Mazandaran University of Science and Technology, Mazandaran

Klimov R, Merkuryev Y (2008) Simulation model for supply chain reliability evaluation. Technological and Economic Development of Economy, Baltic Journal on Sustainability 14:300-311

Lin Y (2009) System reliability evaluation for a multistate supply chain network with failure nodes using minimal paths. IEEE Transactions on Reliability 58:34-40

Lirong Cui X (2008) A study on reliability of supply chain based on higher order Markov chain. IEEE International Conference on Service Operations and Logistics, and Informatics, IEEE/SOLI 2008 2:2014-2017, 40

Liu Y, Wu H, Luo M (2007) A reliability evaluation of supply chain: indicator system and fuzzy comprehensive evaluation. Springer, Boston

Lockamy A, McCormack K (2004) Linking SCOR planning practices to supply chain performance: An exploratory study. International Journal of Operations \& Production Management 24:1192-1218

Manavizadeh N (2005) Presenting a measuring system in supply chain to establish genuine production. M.Sc. Thesis. Faculty of Technology, Tehran University, Tehran

Qing-kui C (2008) Reliability analysis and evaluation on member enterprise of manufacturing supply chain based on BP neural network. In: International Conference on Management Science and Engineering, 2008. ICMSE 2008. 15th Annual Conference Proceedings, Long Beach, 10-12 September 2008

Ren C, Dong J, Ding H, Wang W (2006) A SCOR-based framework for supply chain performance management. IEEE International Conference on Service Operations and Logistics and Informatics, Shanghai, 21-23 June 2006

Riazy A (1997) Designing a decision-making procedure for evaluation, selection and expansion of supplier in supply chain management. M.Sc. Thesis, Faculty of Industrial Management. Iran Science and Technology University, Tehran

Satitsatian S, Kapur KC (2005) An algorithm for reliability bounds computation to evaluate supply chain networks. Thesis, University of Washington, Seattle

Seifbarghy M, Akbari MR, Sajadieh MS (2010) Analyzing the supply chain using SCOR model in a steel producing company. 40th International Conference on Computers and Industrial Engineering (CIE), Awaji, 25-28 July 2010

Shafia MA, Jabal Ameli MS, Fathollah M (2008) A study of the effect of sharing costs in the supply chains based on SCOR. The International Journal of Industrial Management and Production Management, Iran Science and Technology University, 19:30

Shepherd C, Gunter H (2006) Measuring supply chain performance: current research and future directions. International Journal of Productivity and Performance Management 55:242-258

Supply Chain Council (2006) Supply chain operations reference (SCOR) model version 8.0. http://www.scribd.com/doc/2939600/ SCOR-Model-Version-8. Accessed 16 August 2012

Supply Chain Council (2008) Supply chain operations reference (SCOR) model version 10.0: overview. http://supply-chain.org/f/SCOR-Overview-Web.pdf. Accessed 16 August 2012

Stephan J, Badr Y (2007) A quantitative and qualitative approach to manage risks in the supply chain operations reference. 2nd International Conference on Digital Information Management 1:410-417 
Teimouri E (1999) Developing a selection model for suppliers and distribution based on supply chain management approach. Ph.D. Dissertation. Faculty of Industrial Engineering, Iran Science and Technology University, Tehran

Tian G (2009) Research on equilibrium of coordination reliability of supply chain and deepening in division of labor in the perspective of dilemma. 2009 International Conference on Information Management, Innovation Management and Industrial Engineering 2:484-488

Xujie $L$ (2009) Modeling and analyzing supply chain reliability by different effects of failure nodes. 2009 International Conference on Information Management, Innovation Management and Industrial Engineering 4:396-400

Zarei Yaraki A (2004) Information sharing in the supply chain of the country's automobile industry. M.Sc. Thesis. Faculty of Technology and Engineering, Teacher Training (Tarbiat Modarres) University, Tehran

\section{doi:10.1186/2251-712X-8-22}

Cite this article as: Taghizadeh and Hafezi: The investigation of supply chain's reliability measure: a case study. Journal of Industrial Engineering International 2012 8:22.

\section{Submit your manuscript to a SpringerOpen ${ }^{\circ}$ journal and benefit from:}

- Convenient online submission

- Rigorous peer review

- Immediate publication on acceptance

- Open access: articles freely available online

- High visibility within the field

- Retaining the copyright to your article 